\title{
Graphics software and hardware for RT-11 systems
}

\author{
WILLIAM L. PALYA and BLAKE BROWN \\ Jacksonville State University, Jacksonville, Alabama 36265
}

\begin{abstract}
A general-purpose graphics package is described that allows the user to generate figures with a supraset of the basic CalComp plotting subroutines. The software runs under RT-11 on an LSI-11 with $28 \mathrm{~K}$ words of memory. The graphics subroutine library is approximately 200 blocks long. The plotting tasks are passed over an RS 232 line to a simple extension of an inexpensive and commercially available graphics controller. The controller implements these tasks as plotting instructions to a color television, a vector display, and a digital plotter. The graphics subroutines are written in FORTRAN and are invoked by the user as subroutine calls from a FORTRAN program. The graphics controller is a modified Motorola "Micro Chroma 68 Kit." The board is based on the 6808 microprocessor and 6847 video controller. It provides eight graphic modes from 64 by 32 eight-color graphics to 128 by 192 four-color graphics to 256 by 192 two-color graphics. The present software and hardware implements the graphics subroutines as 256 by 192 two-color graphics, as 512 by 512 vector graphics, and as stepping instructions for a digital plotter.
\end{abstract}

A laboratory graphics capability was developed by modifying an inexpensive, commercially available, video graphics controller and writing the software required to enable a user to easily generate and output desired figures. The software and hardware were developed for use on Digital Equipment Corporation (DEC) PDP.11 family computers with the real-time (RT-11) operating system. However, the software was written in a relatively standard FORTRAN, and the graphics controller was designed to receive input over an RS 232 channel. As a result, the graphics software can be modified to run in other environments and the controller can be used with other host computers. The graphics package presently provides for output to black-and-white or color televisions, a vector controller, and a digital plotter. A somewhat straightforward modification would provide the capability to directly drive an X-Y plotter or a vector display.

\section{COMMERCIAL HARDWARE}

Figure 1 provides a block diagram of the graphics hardware. The main computer system is based on an LSI-11 (Doyle \& Palya, 1980; Palya \& Doyle, 1980). We are currently using an unmodified color television as a display device, a Megatek BP 734 vector controller with a Fairchild 737A display, and a Houston Instruments DP 7 digital plotter. The graphics software requires

The authors gratefully acknowledge the contributions of Elizabeth Palya in all phases of producing this system and manuscript. Requests for reprints, software, and schematics should be sent to William L. Palya, Department of Psychology, Jacksonville State University, Jacksonville, Alabama 36265.

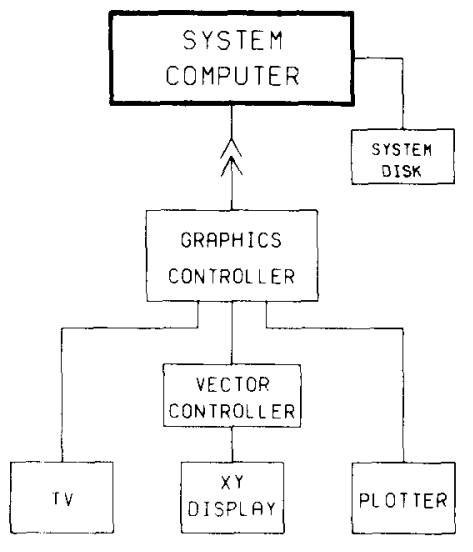

Figure 1. A block diagram of the basic graphics hardware.

about $28 \mathrm{~K}$ words of memory to run, and the library requires about 200 blocks of disk storage.

The graphics controller is a modified Motorola "Micro Chroma 68 Kit." The board is based on the 6847 video controller and provides eight graphic modes from 64 by 32 eight-color graphics, to 128 by 192 four-color graphics, to 256 by 192 two-color graphics. Figure 2 provides a block diagram of the Micro Chroma 68 board. This commercial board is a standalone system and contains a 6808 microprocessor, a $2 \mathrm{~K}$ monitor, $8 \mathrm{~K}$ user RAM, a keyboard port, a "Kansas City standard" tape port, $6 \mathrm{~K}$ video display RAM, and circuitry to connect to an unmodified color television. Motorola provides the printed circuit board and major chip set to universities for $\$ 89$. The additional parts needed to complete the kit cost approximately $\$ 150$. 


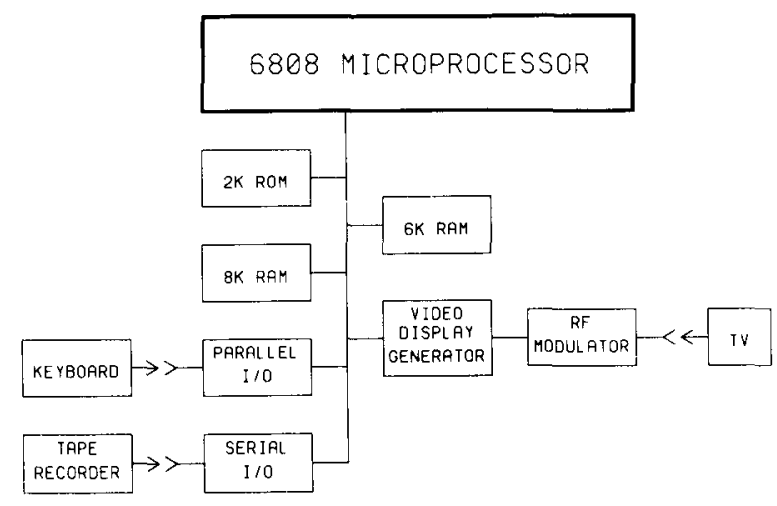

Figure 2. A block diagram of the commercially available Micro Chroma 68 board.

\section{CUSTOM HARDWARE}

The present system did not implement the monitor, the tape port, or the keyboard port that were available on the Micro Chroma 68 board. Rather, the present implementation uses the board as a dedicated peripheral controller that is downline loaded through an RS 232 port. Figure 3 provides a block diagram of the graphics controller. A $1 \mathrm{~K}$ communications monitor in PROM, interfaces for the vector display (RS 232), and the digital plotter (parallel I/O adapter and one shots) were implemented on the "kluge" area provided on the Micro Chroma board. With the addition of parallel adapters, digital-to-analog converters, and task software, a vector display or an X-Y plotter can be directly interfaced.

\section{COMMERCIAL SOFTWARE}

The graphics subroutines are invoked by the user as subroutine calls from a FORTRAN program running under DEC's RT-1 1 operating system. Figure 4 illustrates the overall architecture of the commercial software used in displaying graphics. The user writes the program in FORTRAN, including the calls to the graphics subroutines. This program is compiled and then linked with the COMLIB library, which produces the machinerunnable program. The graphics library, COMLIB, emulates the CalComp "Host Computer Basic Software," or HCBS (Calcomp Computer Products, 1976, 1977). In addition, it also includes other graphic subroutines that provide for the more convenient generation of the type of figures that are typically used in psychology.

\section{CUSTOM SOFTWARE}

The custom software consists of three main groups: the initialization and utility software, which sets up and carries out the interprocessor communication; the graphics processor software, which receives the informa- tion from the main system, processes it, and controls the appropriate display device; and the library of graphics subroutines. Figure 5 illustrates these custom software elements in the graphics package.

The initialization and utility software is invoked by a subroutine call to PLOTS, which must be called before any other graphic subroutine. It is a FORTRAN routine that determines the display device requested by the user, obtains and downline loads the appropriate software for the graphics controller, obtains and installs the appropriate data passing software for the LSI-11, and initializes the graphics software.

The graphics controller monitor contains an input routine in PROM that loads in the task-specific software to control the requested display device from the RS 232 channel. The graphic controller then inputs graphics commands into a $6 \mathrm{~K}$ input buffer. This typically releases the main processor from a graphics tasks almost immediately. The task-specific software in the controller imple-

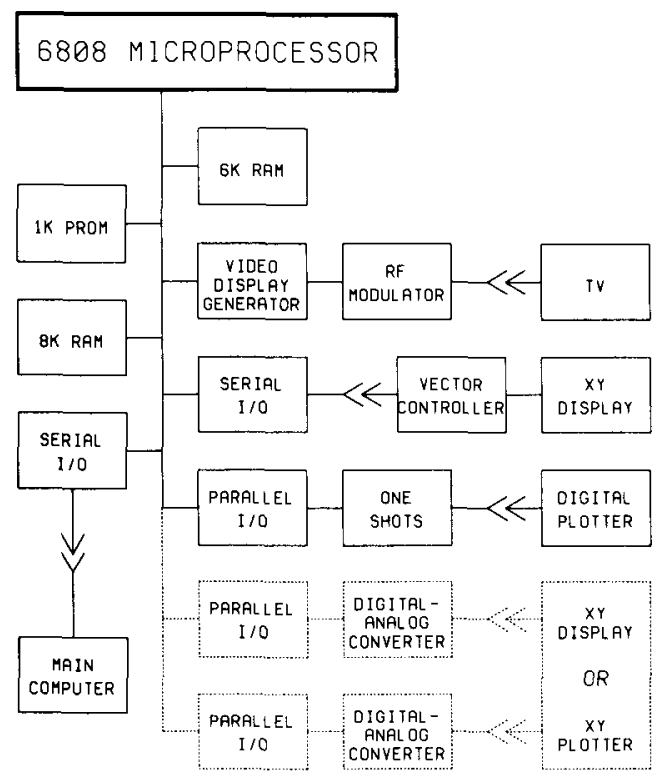

Figure 3. A block diagram of the Micro Chroma 68 board as modified for use as a graphics controller.

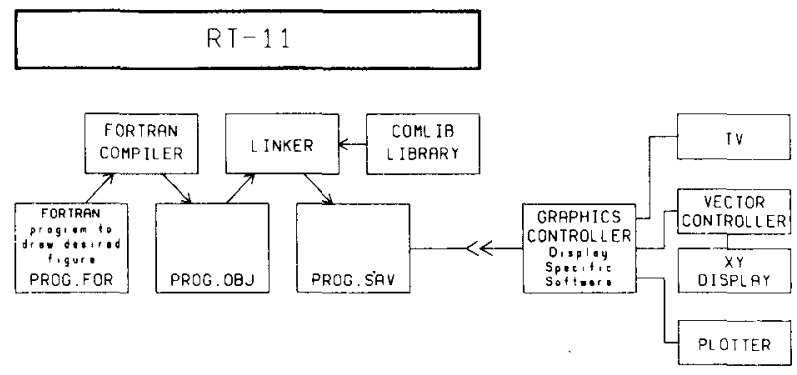

Figure 4. Architecture of the commercial software used in displaying graphics. 


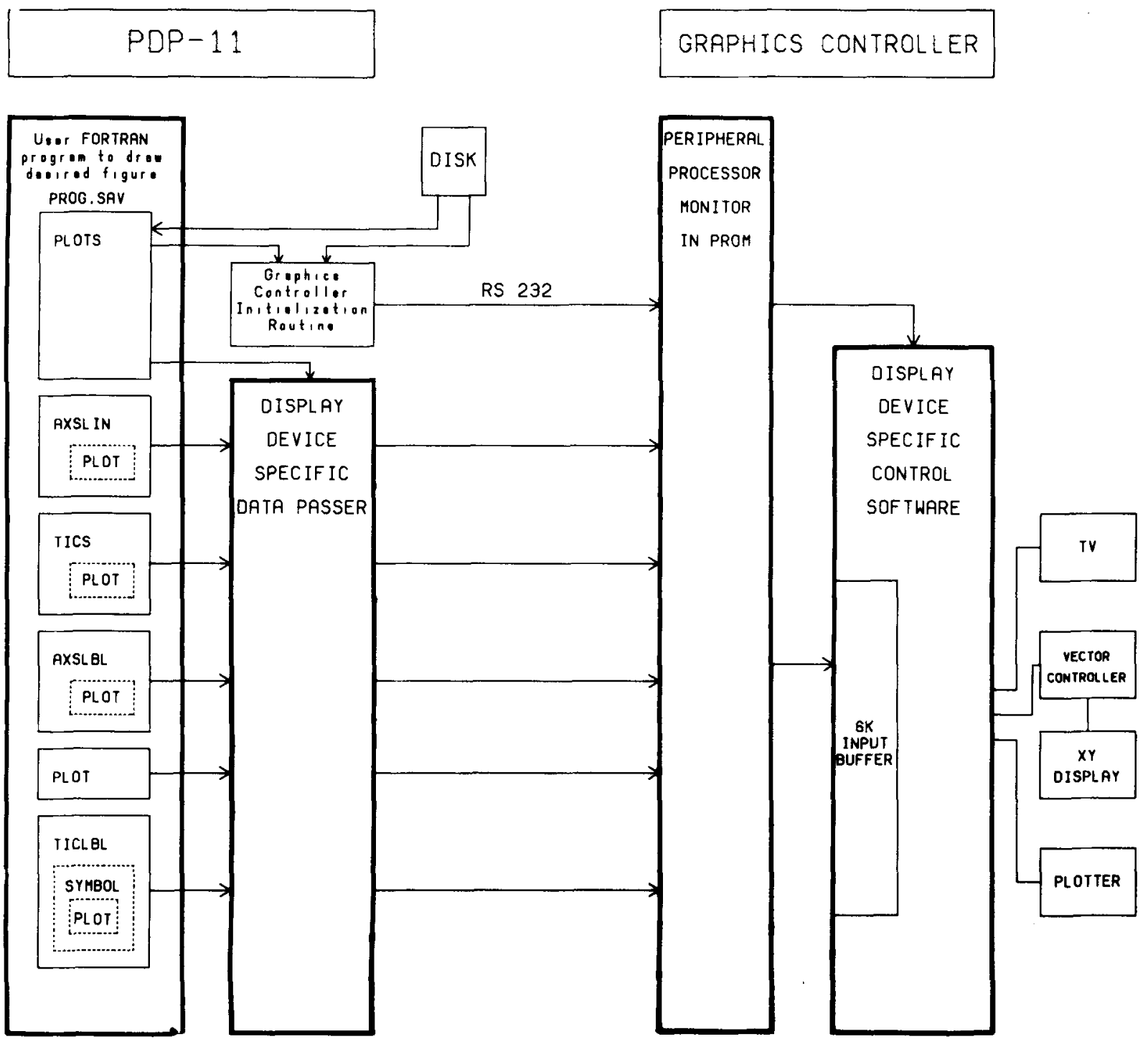

Figure 5. Overall architecture of the software used in displaying graphics.

ments the graphics input as 256 by 192 two-color raster graphics, as 512 by 512 vector graphics to a Megatek graphics controller, or as stepping instructions for a Houston Instruments DP 7 plotter.

The library of graphics subroutines is detailed in the Appendix. They are for the most part hierarchical, with PLOT as the kernel or basic HCBS subroutine. PLOT either simply moves the "pen" to some $x, y$ coordinate or draws a line while moving the pen. Virtually all other subroutines call PLOT to implement their specific functions. We have supplemented PLOT with MOVE, which also allows control of the line type while moving the pen.

AXIS is the CalComp HCBS subroutine that draws axes, adds tic marks, numbers the tics, and labels the axes. Unfortunately, it provides only a very restricted and generally unacceptable format. The present library superceded AXIS with AXSLIN (draw axis line), TICS (draw tic marks), TICLBL (label the tic marks), and AXSLBL (label the axis). These routines provide complete and converient control of each element and allow the user to create figures with a satisfactory appearance.

SYMBOL and NUMBER are the CalComp subroutines for drawing symbols and numbers. SYMBOL draws designated characters, and NUMBER draws the characters that specify the value of a number. SYMBOL has been modified to contain a character set with a better appearance, as well as a character set for the vector display. TEXT has been added to the library. It centers a string of characters between specified points and provides any desired character rotation. 
The HCBS library also contains several utility subroutines. LINE is the CalComp subroutine that draws a line. It has been expanded with ILINE (draw an interrupted line), DRAWLN (draw a line with data from the disk), NEWLIN (change line type), PENUP, PENDN, and HOME (return to current origin). Several other HCBS support subroutines are included in the library, such as NEWPEN (change pens), SCALE (scale data to fit axis), WHERE (returns $x, y$ coordinate of current pen location), and FACTOR (draws figure to specified scale). Calling FACTOR (.5) reduces the entire figure by $50 \%$.

\section{REFERENCES}

CalComp Computen Products. CalComp software reference manual. Anaheim, Calif: Author, 1976.

CalComp Computer Products. Programming CalComp electromechanical plotters. Anaheim, Calif: Author, 1977.

DoYle, A. F., \& PalYA, W. L. A hierarchical LSI-11 system for real-time control, interevent time storage, and data analysis. Behavior Research Methods \& Instrumentation, 1980, 12, 221-231.

Palya, W. L., \& Doyle, A. F. A simple LSI-11 system for realtime control, interevent time storage, and data analysis. Behavior Research Methods \& Instrumentation, 1980, 12, 210-220.

\section{APPENDIX}

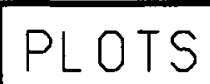

INITIAL IZES GRAPHICS SYSTEM

DEVICE

CHARACTER SET

\section{PLOT}
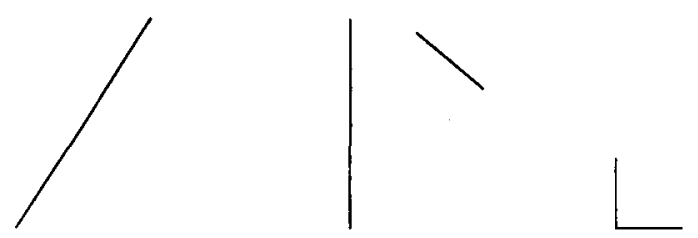

MOVES PEN - MANIPULATES ORIGIN

$X . Y$ COORDINATE OF DESTINATION

PEN UP / PEN DOWN

REESTABL ISH ORIGIN

RETURN CURRENT LOCATION

CLEAR SCREEN

NEWL IN

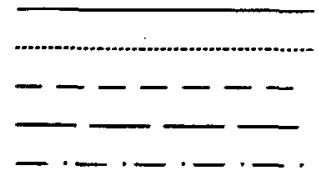

CHANGES LINE TYPE

SOL IO

DOTTED

DASHEO

BROKEN

DOT/DASH
NEWPEN

\section{CHANGES PEN}

PEN 1. 2. OR 3
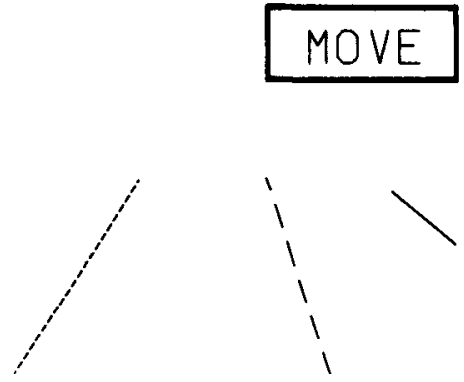

MOVES PEN - MANIPULATES ORIGIN

$X . Y$ COOROINATE OF OESTINATION

PEN UP / PEN DOWN

REESTABL ISH ORIGIN

RETURN CURRENT LOCATION

OESIREO PEN

LINE TYPE (SOLID. DOTIED, DASHED. BROKEN. DOT-DASH)

WHERE 


\section{HOMF}

MOVES PEN TO CURRENT ORIGIN
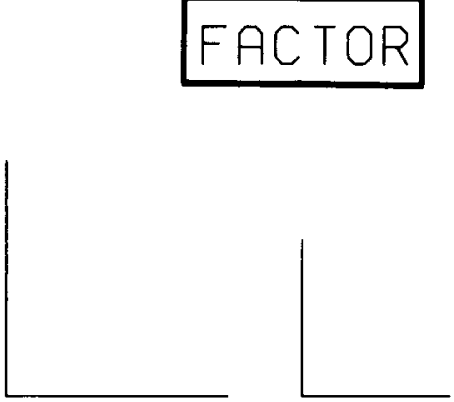

\section{CHANGES SIZE OF FIGURE}

PROPORTION OF ORIGINAL
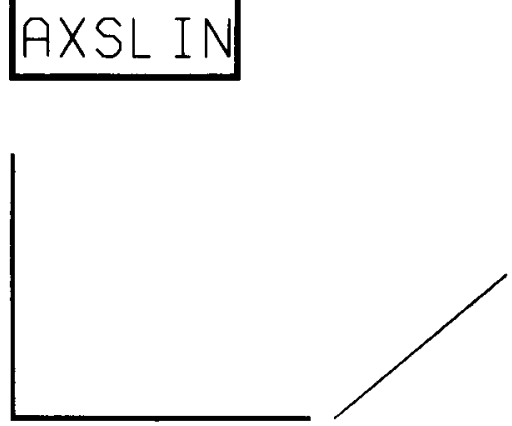

DRAWS AXIS LINE

AXIS ANGLE

AXIS LENGTH

NUMBER OF OFFSET RETRACES

CENTEREO / ONE SIDE

DISTANCE BETWEEN RETRACES
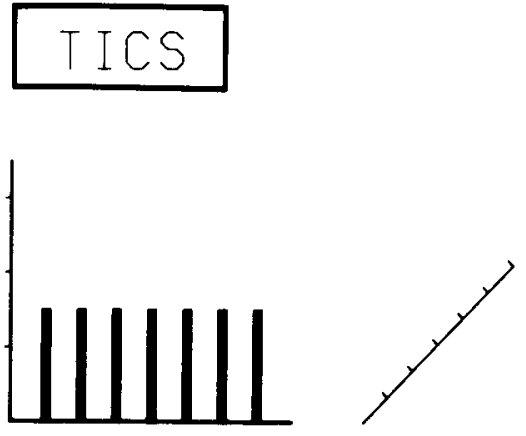

DRAWS TIC MARKS

AXIS ANGLE

AXIS LENGTH

DISTANCE TO FIRST TIC

SPACE BETHEEN TICS (MANUAL)

HOH MANY TICS (AUTO)

LENGTH OF TICS

WIOTH OF TICS

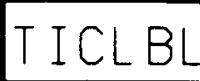

1. 3. 5. 7.9.

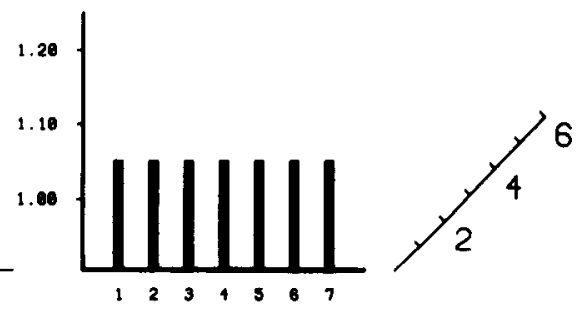

LABELS TIC MARKS

AXIS ANGLE AXIS LENGTH

DISTANCE TO FIRST NUMBER SPACE BETHEEN NUMBERS (MANUAL)

HOH MANY NUMBERS (AUTO)

VALUE OF FIRST TIC

VALUE INCREMENT PER TIC

NUMBER OF DECIMAL PLACES

HEIGHT OF NUMEERS

ROTATION OF NUMBERS

DISTANCE FROM AXIS 

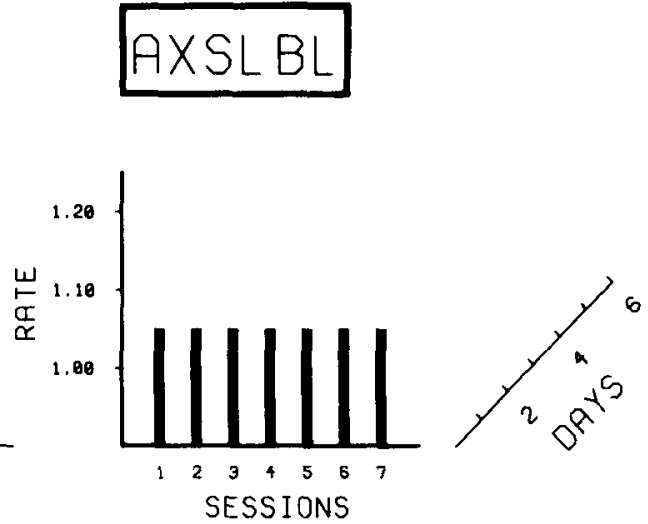

\section{LABELS THE AXIS}

AXIS RNGLE

AXIS LENGTH

NUMBER OF CHARACTERS

OESIRED TEXT

CHARACTER SIZE

CHARACTER ROTATION

DISTANCE FROM AXIS

OFFSET FROM CENTERED

\section{INE}

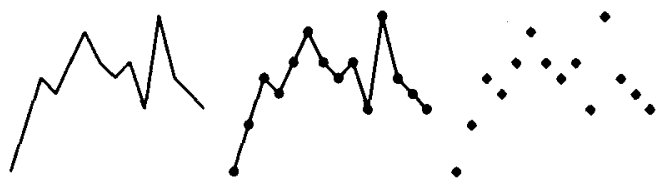

DRAWS A L INE

RRRAY OF $X$ COORDINATES

ARRAY OF $Y$ COOROINATES

NUMBER OF DATA POINTS

ARRAY INDEX

LINE TYPE

CONNECTED / NOT CONNECTEO POINTS

SYMEOLS I NO SYMBOLS

FREOUENCY OF SYMBOLS

OESIREO SYMBOL

\section{SCALE}

\section{PREPROCESSES DATA}

FIRST ELEMENT IN RRRAY

NUMBER OF ELEMENTS IN ARRAY

ARRAY INDEX

LENOTH OF AXIS ON TO WHICH ARRAY MUST FIT

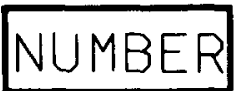

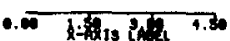

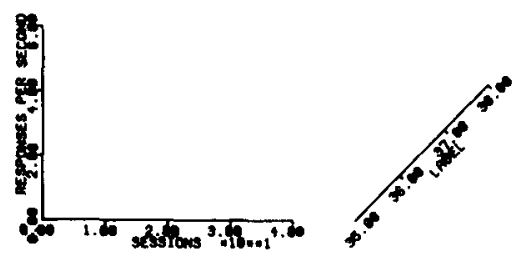

DRAWS AXIS. TIC MARKS. AND LABEL

$X . Y$ COORDINATE OF AXIS ORIOIN

AXIS ANOLE

AXIS LENOTH

VALUE OF FIRST TIC

VAL UE INCREMENT PER TIC

DESIRED TEX

NUMOER OF CHARACTERS

\section{DRAWS A NUMBER}

$X . Y$ COOROINATE OF START OF NUMEER HEIGHT OF NUMBER

VALUE OF NUMBER

ANGLE OF NUMBER STRING

FORMAT

NUMBER OF DECIMAL PLACES

INTEGER I REAL

TRUNCATION 


$$
\text { TEXT }
$$

\section{DRAWS CENTERED TEXT}

PAIR OF $X$. Y COORDINATES

NUMBER OF CHARACTERS

DESIRED TEXT

HEIGHT OF CHARACTERS

ROTATION OF CHARACTERS

OFFSET FROM CENTERED
SYMBOL

\author{
ABCDEFGHI JKL MN \\ ABCDEFGHIJKL MNOPORSTUVHXYZ \\ obcdefghijk|mnapqreturexyz

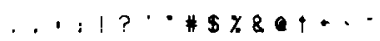 \\ 01234567895 or $f 5 \pi$ \\ $><=+* 1 / 16][1]$
}

$\diamond \bullet 0 \bullet \square \triangle \Delta * \star \Delta$

$A B<D \in F \& H I$ JKLLMNOPQRSTUVHXYZ

\section{DRAWS SYMBOL}

$X$ Y COORDINATE OF START OF TEXT ANGLE OF TEXT STRING NUMBER OF CHARACTERS DESIRED TEXT

HEIGHT OF CHARACTERS

PLOTTER / CRT SYMBOL SET 